\title{
Access to sustainably produced food: An investigation of organic food availability in Manhattan, New York
}

\author{
Laura Mirsch, ${ }^{a}$ Department of Nutrition, Food Studies and Public Health, New York University \\ Carolyn Dimitri, ${ }^{\mathrm{b}},{ }^{*}$ Department of Nutrition, Food Studies and Public Health, New York University
}

Submitted 25 April 2011 / Revised 20 June 2011, 13 October 2011, and 1 January 2012 / Accepted 11 January 2012 /

Published online 26 April 2012

Citation: Mirsch, L., \& Dimitri, C. (2012). Access to sustainably produced food: An investigation of organic food availability in Manhattan, New York Journal of Agriculture, Food Systems, and Community Development, 2(3), 193-209.

http://dx.doi.org/10.5304/jafscd.2012.023.001

Copyright (C) 2012 by New Leaf Associates, Inc.

\begin{abstract}
Increasing access to food and improving the sustainability of producing and marketing food are both goals of the "food movement." One problem embedded in these dual goals is that improving access relies on low-priced food, while increasing sustainability of the food system necessarily raises prices. Further complicating the discussion is the fact that while the definition of a sustainable food system is intuitive, it is also vague, which does not
\end{abstract}

a Graduate student, Department of Nutrition, Food Studies and Public Health; New York University; 411 Lafayette Street $5^{\text {th }}$ Floor; New York, NY 10003 USA

b, * Corresponding author: Carolyn Dimitri, Associate Professor; Department of Nutrition, Food Studies and Public Health; New York University; 411 Lafayette Street, $5^{\text {th }}$ Floor; New York, NY 10003 USA; carolyn.dimitri@,nyu.edu

\section{Disclosure}

Funding for this research was partially provided by USDA's National Institute of Food and Agriculture, formerly known as National Research Initiative, under NRI Award 2007-04473. make an analysis of sustainable food simple. Thus we use organic food as a case study to provide insight into the availability of a sustainably produced (but not necessarily sustainably marketed) food. This paper is a first step toward exploring potential links among availability, access, and consumers. Using a new data set of in-store organic food availability in Manhattan, mapping suggest that stores that carry a wider range of organic products are located in neighborhoods with populations that are both highly educated and affluent. Neighborhoods with a higher proportion of black households have little access to organic food. Bivariate correlation coefficients find that the relationship between education and organic food access increases as the level of education rises, that median household income is positively associated with organic food availability, and that the relationship between the proportion of black residences is weakly and negatively correlated with organic food availability. 


\section{Keywords}

demographics, food access, GIS, organic food availability

\section{Introduction and Literature Review}

Food access and sustainability of food production and marketing have both been targeted as aspects of the food system that are in need of change. Those working on the ground with the aim of increasing food access seek to address an immediate need: feeding people who have limited access to food, due either to low income or lack of availability in nearby locations. Similarly, those working on the production and marketing aspects of the food system are committed to increasing opportunities for farmers and consumers by creating alternative markets as well as supporting sustainable farming practices, such as organic farming. The task of simultaneously meeting both goals, or making progress toward these goals, appears daunting.

An equitable and just food system, in principle, should be able to satisfy both goals, yet from at least one perspective, that of monetary cost, doing so appears impossible. From the food access side, there is a general notion that meeting the health needs of low-income consumers is best accomplished by increasing access to low-priced, nonluxury food items (Drewnowksi \& Eichelsdoefer, 2009). The necessity of increasing access to food that sells for low prices appears to be a foregone conclusion, and as a result, the focus on low prices requires the food be produced and marketed in our conventional food system. Yet this food is the product of a system that carries negative social and environmental externalities that are well documented (see for example, Kirschenmann, Stevenson, Buttel, Lyson, \& Duffy, 2008; Pimental \& Pimental, 2008; Tilman, Cassman, Matson, Naylor, \& Polasky, 2002). Further, those aspects of the food system most often criticized — such as large farms, large processing facilities, mass produced packaged foods, environmental pollution, and low wages - are exactly those that contribute to low food prices for consumers.

While an intuitive understanding of a sustainable, just food system is easy to imagine, specific details about the types of farming practices, wages, and distribution channels that compose a sustainable food system are harder to pin down. The farm level is the simplest to think about in terms of sustainability, but even defining and measuring farm-level sustainability is not an easy task. Many environmentally friendly farming practices exist, but there is no concrete definition of how many or which practices are essential to fairly state that a farm is "sustainable" (Tilman et al., 2002). The one production system that is most easily to describe as sustainable is organic agriculture, which encompasses well-defined farm practices, an enforcement system, and, as compared to conventional agriculture, is significantly less damaging to the environment (Greene, Dimitri, Lin, McBride, Oberholtzer, \& Smith, 2010).

Once food leaves the farm and moves through the supply chain toward the consumer, there are no guidelines for which elements should be considered necessary parts of a sustainable food system. And how is sustainable marketing connected to sustainable production? For example, organic food - which satisfies on the element of farm sustainability - may not be marketed and distributed in sustainable ways. In fact, the suggestion that organic food has become part of an "agro-industrial complex" reveals some opposition to organic food (see for example, Fromartz, 2006; Pollan, 2001). The critique of organic likely stems from the failure of the national organic standard to encompass broader goals of the food movement, such as issues related to labor, equity, and access, which are all tied to perceptions of sustainability of the food system.

That said, it is safe to say that any efforts to change the conventional food system, through organic agriculture, other forms of environmentally friendly farming practices, smaller farms, and/or alternative distribution systems, are costly. The higher production and marketing costs translate to higher prices for consumers. And thus a conundrum exists: increased food access relies on lowpriced food, while the consequence of a sustainable food system is higher-priced food. This conflict raises the question of how can both goals be met without having to sacrifice one important value of 
the food movement? While we are unable to fully explore the question in this paper, we open the discussion of these issues with an investigation of availability of the most easily defined sustainable food product (at least from the perspective of the farm level): organic food.

We rely on geographic information systems (GIS) to examine patterns of organic food availability in the context of several socioeconomic characteristics in Manhattan, New York. GIS methods are widely used to examine issues related to food availability and access (see for example, Ghirardelli, Quinn, \& Foerster, 2010; Kirkpatrick \& Tarasuk, 2010; Rose, Bodor, \& Rice, 2011). The choice of demographic characteristics mapped follows from the literature on organic food consumers, which finds that, after accounting for income and other factors, consumers with higher levels of education are more willing or likely to purchase organic products (Dettmann \& Dimitri, 2010; Fotopoulos \& Krystallis, 2002; Krystallis, Fotopoulos, \& Zotos, 2006; Magnusson, Arvola, Koivisto Hursti, \& Åberg, 2001; O’Donovan \& McCarthy, 2002; Zepeda \& Li, 2007). Research has yielded conflicting results on the impact of income and race on the likelihood of buying organic food (Durham, 2007; Govindasamy \& Italia, 1990; Loureiro, McCluskey, \& Mittlehammer, 2001). Access to organic food, approximated by distance to a Whole Foods retail store, suggests that availability likely has a measurable effect on consumption of organic food (Dimitri \& Dettman, 2011).

This paper contributes to the literature by exploring the availability of and access to the most easily defined sustainable food product — organic food - in a major urban area in the United States. One appeal of the work is that it presents an easily replicable methodology. Adoption of the methodology by researchers in multiple locations would make possible comparisons across different regions in the U.S., and could be extended easily to include food with other characteristics, such as fair trade or local food.

\section{Applied Research Methods}

The study area is Manhattan, New York, a densely populated area covering approximately 23 square miles $(60$ square $\mathrm{km})$ that contains very affluent (for example, Upper East Side) and very poor (for example, Harlem) neighborhoods. Despite Manhattan's reputation for wealth, the city has a fair number of low-income households: five-year estimates for 2005-2009 reveal that 35\% of households have an annual income of less than USD35,000 per year (American Community Survey, 2009). The median household income in 2009 was USD59,000, and the mean household income was USD98,000, indicating that a relatively small number of households have very high income (American Community Survey, 2009). Sixty-one percent of public schoolchildren were eligible for free lunch in 2008 (Economic Research Service, 2011). Nearly $10 \%$ of families and $14 \%$ of individuals had incomes below the poverty level in 2009; these levels exceed those of the total U.S. population. Forty percent of female-headed households with children under 18 years old had income below the poverty line in 2009 , which also exceeds the general population (American Community Survey, 2009).

The majority of Manhattan residents are white, but there is significant presence of other ethnic groups in the city; the ethnic diversity is not far from the nation as a whole. The ethnic distribution of residents in Manhattan is $60 \%$ white, $16 \%$ black, $10 \%$ Asian, and $12 \%$ some other race. Twenty-four percent are Hispanic or Latino, of any race (American Community Survey, 2009). In comparison, in 2002, the U.S. population (in terms of residents) was distributed as $69 \%$ white, $13 \%$ black, $4 \%$ Asian, and slightly more than $13 \%$ were Hispanic or Latino (U.S. Census Bureau, 2004). The one characteristic that does not exhibit much variation is education: $85 \%$ of adults 25 years or older were high school graduates between 2005 and 2009 , with close to $58 \%$ holding an undergraduate degree or higher (U.S. Census Bureau, 2011).

Most researchers studying access to food either sample a small area or purchase establishment data, such as that available from Dun and Bradstreet. Besharov, Bitler, and Haider (2011) point out that establishment data often overlook the multiplicity of retail venues where consumers purchase food. Studies that focus on a small scale are easier to implement, but may yield results that are applicable 
only to a small geographic area and are not broadly representative of the U.S. In designing this project, feasibility, dollar and time cost, and the robustness of research results were considered. Ultimately, we decided that the study would cover the entire borough of Manhattan, which would provide a balance of practicality and robustness. Given the denseness of the study area, all retail stores could be identified by walking around the city. And while Manhattan is small in terms of land mass, it is a dense city with 1.6 million residents in 2010 (U.S. Census Bureau, 2011).

Data collection occurred in two phases. The first phase, conducted by 25 food studies graduate students in a course on food systems at New York University, took place during the fall of 2010. This phase entailed dividing Manhattan into 25 segments, which groups walked through, identifying the names and addresses of each store in their region. Stores that sold fluid milk (or more) were included in our dataset; restaurants or retail outlets that sold take-out food only were excluded.

Approximately 1,300 stores were located, including Manhattan's bodegas, convenience stores, small grocers, drug stores, big-box stores, specialty food retailers, and supermarkets. The uniqueness of food retailing in Manhattan was illuminated by the data collected, as few stores in the city are traditional chain supermarkets and there are a high proportion of independent grocers. The second phase of data collection, conducted in January 2011, consisted of visiting each of the stores initially identified to ascertain the availability of organic food and to collect additional data. A team of five data collectors was hired to (1) check the initial store list, (2) locate stores missing from the initial list, and (3) collect in-store data on the availability of organic, conventional, and local versions of 24 products. Every effort was made to locate all stores that fit our criteria for inclusion. Farmers' markets were excluded from the second phase of data collection because the collectors were in the field during a time the majority of markets in Manhattan were closed.

A short survey instrument that guided the data collection included a list of food products (see table 1); these products were selected because they were healthy and could be used at home for meal preparation. The products were also selected because they include good representation of the two largest organic food categories in the U.S. dairy and fresh produce — which together composed about $50 \%$ of retail organic sales in 2009 (Nutrition Business Journal, 2010). While other products, such as breakfast cereals and packaged food products, are important in terms of retail sales, the decision to exclude packaged products was made in light of the scarcity of shelf space in Manhattan. Real estate is costly, stores are small, and as a result, most stores in Manhattan carry fewer products, tightly jammed onto shelves, than

Table 1. Organic Food Availability, Manhattan, New York, January 2011 ( $N=1,260)$

\begin{tabular}{lcc}
\hline & \multicolumn{2}{c}{ Stores } \\
\hline Organic product & number & percent \\
\hline Apples & 119 & $9 \%$ \\
\hline Baby carrots & 111 & 9 \\
\hline Bananas & 72 & 6 \\
\hline Beef & 38 & 3 \\
\hline Broccoli (frozen) & 101 & 8 \\
\hline Carrots & 82 & 7 \\
\hline Cheese & 135 & 11 \\
\hline Chicken & 68 & 5 \\
\hline Corn (frozen) & 109 & 9 \\
\hline Eggs & 290 & 23 \\
\hline Grapes & 2 & 0 \\
\hline Lettuce & 40 & 3 \\
\hline Lettuce (packaged) & 137 & 11 \\
\hline Milk & 437 & 35 \\
\hline Mixed vegetables (frozen) & 100 & 8 \\
\hline Onions & 50 & 4 \\
\hline Pears & 56 & 4 \\
\hline Peas (frozen) & 97 & 8 \\
\hline Potatoes & 62 & 5 \\
\hline Potatoes (frozen) & 87 & 7 \\
\hline Strawberries & 23 & 2 \\
\hline Strawberries (frozen) & 5 \\
\hline Yomatoes & & 6 \\
\hline
\end{tabular}

Source: Data collected by authors and research team. 
suburban supermarkets. The final dataset, after verification and cross-checking by the team of data collectors, included 1,260 stores. Other data collected, but not used in this study, included availability of organic, local, and conventional versions of the 24 products, the number of cash registers, whether a store accepted any type of federal nutrition benefits, and hours and days open. Seasonality influences the availability of perishable foods, and several of the products on the list were not available in Manhattan in the dead of winter. For example, fresh strawberries are in season during the spring, while grapes are in season from May to December. As the table shows, the organic products carried by the greatest number of stores are milk, eggs, and yogurt. Frozen organic products are not widely carried in Manhattan food retail stores, which may be the result of scarce freezer space.

The availability of organic food was based on the breadth of different organic products stores carried. To capture availability, a simple index was created, calculated as the percentage of these 24 products for sale in each store. If a store had all of the 24 products, the index equaled 100. If a store had none of the organic products, its index equaled 0 , while the index for a store with 12 of the organic products was 50 . The index provides a discrete "yes or no" measure of availability, and does not differentiate between stores that might have three brands of organic milk versus just one brand. Overall, the index ranged from 0 to 100, with 61\% of the stores not selling any organic products. Of those selling organic products, the mean value of the index was 22 , while the median was 13 , suggesting that there are many stores selling a few organic products. In fact, only 79 stores of the 1,260 carried 12 or more of the organic products on the list, and only one store carried all 24 .

\section{Results and Discussion}

This research has two key questions: (1) is organic food available for sale throughout all of Manhattan, and (2) which socioeconomic characteristics are related to the availability of organic food? The socioeconomic factors explored are income, education, income and education combined, and race (just for black households). The analysis is based on maps generated by the GIS software ArcGIS, in which socioeconomic characteristics from the American Community Survey (2009) were mapped and compared alongside the geocoded store locations.

\section{Organic Food Availability}

Proximity is important for urban food shoppers in Manhattan. Most consumers shop for food on foot and some use public transportation, while others pay to have their food delivered. Food delivery fees vary by distance from the store, with costs higher for deliveries further away. Just 13\% of Manhattan residents have access to a car, but even for those who do, shopping by car is impractical given traffic congestion and lack of parking (American Community Survey, 2011). Thus, distance from stores selling organic food is likely to have a large impact on whether a household purchases and consumes organic food. Further, this line of reasoning suggests that the distance a Manhattan consumer will travel to a food store is significantly shorter than that of a suburban shopper.

As figure 1 shows, food stores are located throughout the city, with the exception of Central Park (the large rectangle in the middle of the city), and Alphabet City (the lower right corner of the city). Each dot represents a food retail store. The map does not identify store types, but the individual observations (summaries available from authors upon request) reveal that small corner stores, stocked mostly with packaged foods and beer, dominate traditionally less affluent areas (roughly speaking the areas north of Central Park; see figure 1 for more detail on income). The open circles signify stores with no organic products, while the triangles indicate retailers that have an index of value 40 or higher (or 10 or more of the organic products on list). The square boxes represent the stores that carry from 1 to 9 of the organic products on the list. Figure 2 maps the location of farmers' markets in Manhattan. The map indicates the number of days the market is open, and differentiates between seasonal and yearround markets.

Patterns are clear and suggestive: stores with no organic products are located throughout Manhattan, but are concentrated in the neighbor- 
hoods above Central Park, many of which are lower income, and include Harlem, Inwood, and Washington Heights. Stores with a wide range of organic products are located throughout the city as well, but are concentrated in the areas on each side of Central Park (the more affluent areas of the Upper West and Upper East sides), and in the downtown areas near Greenwich Village, Chelsea, Soho, and Tribeca. The majority of retail outlets located in the neighborhoods below the northern boundary of Central Park carry organic products. Nearly all of the retail venues that sell 11 or more of the organic products on the list are located below the northern boundary of the park as well. Farmers' market locations follow a similar pattern (figure 2): only two year-round markets are north of Central Park, and the majority are located in area below the northern park boundary.

In many ways, the findings are not surprising. Food stores are businesses that choose to locate in areas that will yield the highest expected profits. The decision of which products to carry is also based on profit maximization. Thus, the dearth of a wide range of organic food in the less affluent parts of the borough is not unexpected. However, by shifting the focus from the stores with many organic products to those with an index in the range of 3-40, which roughly translates to between 1 and 10 different products, the map reveals that at least some organic food is available throughout much of Manhattan. This suggests that retailers find that carrying at least some organic food is profitable.

\section{Socioeconomic Characteristics and Organic Food Availability}

Previous research on organic consumers suggests that a relationship exists between socioeconomic characteristics of consumers and their likelihood of buying organic food (Dettmann \& Dimitri, 2010; Fotopoulos \& Krystallis, 2002; Krystallis et al. 2006; Magnusson et al., 2001; O’Donovan \& McCarthy, 2002; Zepeda \& Li 2007). We investigate whether availability of organic food follows the same patterns, regarding socioeconomic characteristics, as the likelihood of buying organic food. Data on the demographic characteristics across the census tracts of Manhattan are from the American Community Survey (2009). The U.S. Census Bureau collects this data from a stratified sample, monthly and annually, and develops statistically valid annual data for income, education, ethnicity, and other socioeconomic variables. Our analysis specifically examines the spatial relationship between organic food availability and (1) the percentage of black households in a census tract, (2) household income, (3) level of education attained, and (4) select combinations of household income and education. The current work relies on maps as basic descriptors of how patterns of organic food availability vary with socioeconomic indicators. Future research will incorporate techniques beyond GIS maps, including spatial econometric analysis.

Research into the demographic profile of organic food consumers indicates that black households, when compared to white households, are statistically less likely to purchase organic food. Further, food access studies indicate that supermarkets are not as prevalent in neighborhoods with mostly black households. These findings, unique to black households, raise the question of the black consumer's access to organic food. Figure 3 maps the availability of organic food in conjunction with the distribution of the percentage of black households across census tracts in the city; a darker map color indicates a higher percentage of black households in a census tract. The pattern suggests that very few stores with a high availability of organic food are located in predominantly black neighborhoods. A partial explanation for this pattern is that supermarkets are less likely to be available in neighborhoods with a high proportion of black residents (Powell, Slater, Mirtcheva, Bao, \& Chaloupka, 2007), and thus it is not surprising that organic food is less available as well. Future research into the relationship between access to organic food for black households is warranted; it is likely that a complicating factor is related to the general barriers to food access caused by a lack of food stores or the type of food stores in neighborhoods with mostly black residents. 
Figure 1. Organic Food Availability in Manhattan, New York, January 2011

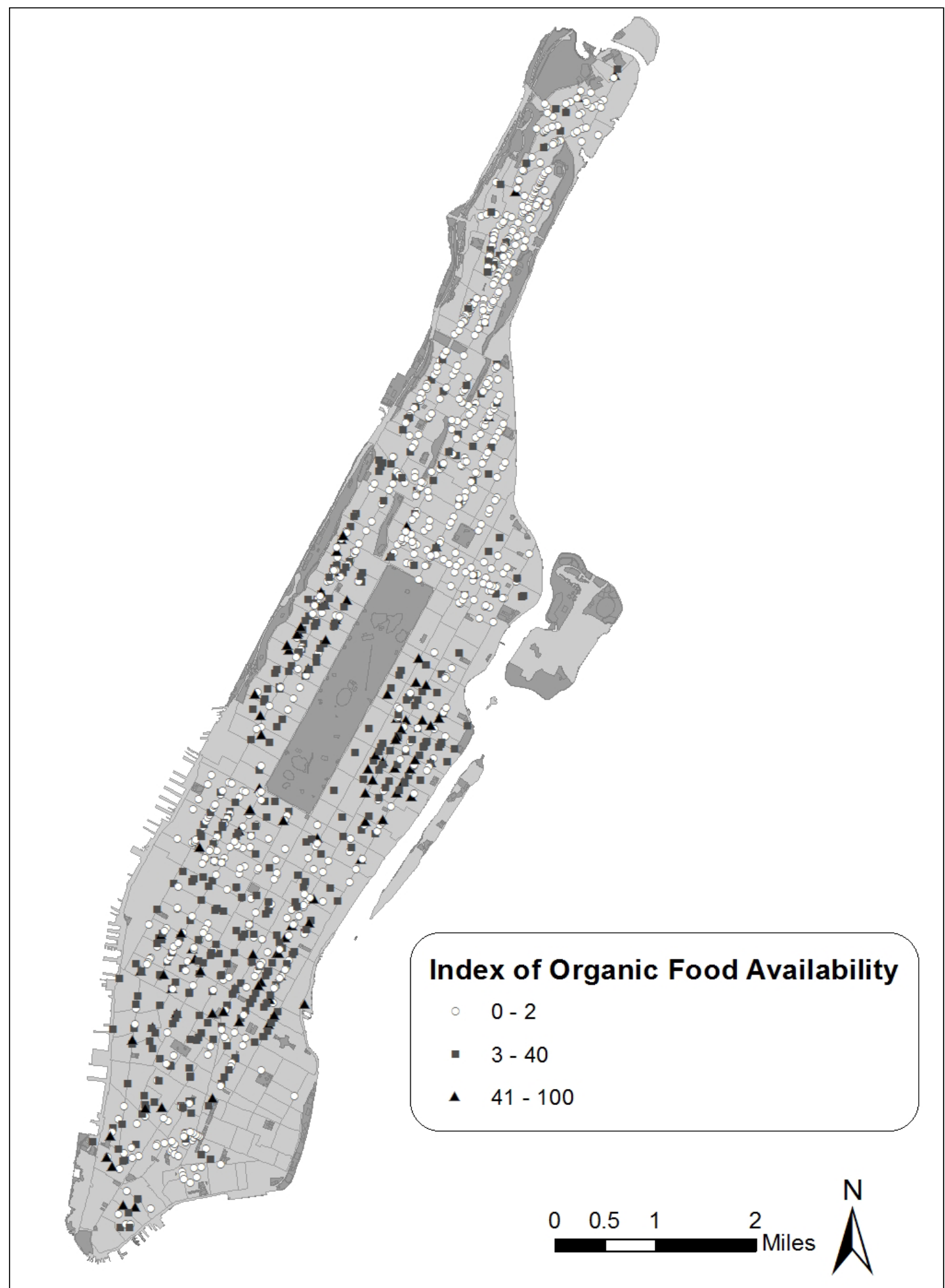

Source: Data collected by authors. 
Figure 2. Location of Farmers' Markets in Manhattan, New York, 2011

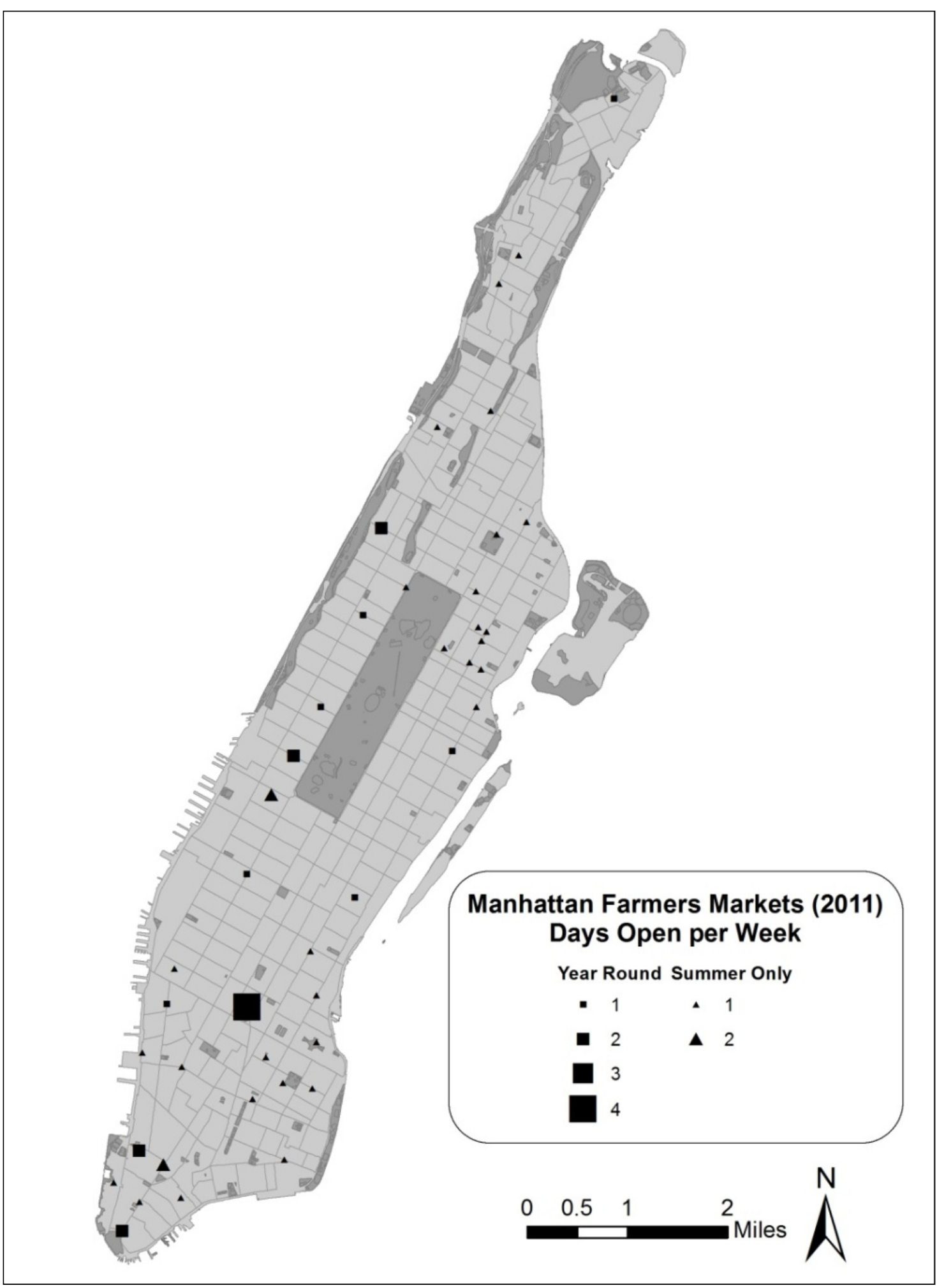

Sources: Agricultural Marketing Service, USDA, 2011; http://www.grownyc.org; http://www.harvesthomefm.org 
Figure 3. Organic Food Access for Black Households in Manhattan, New York, January 2011

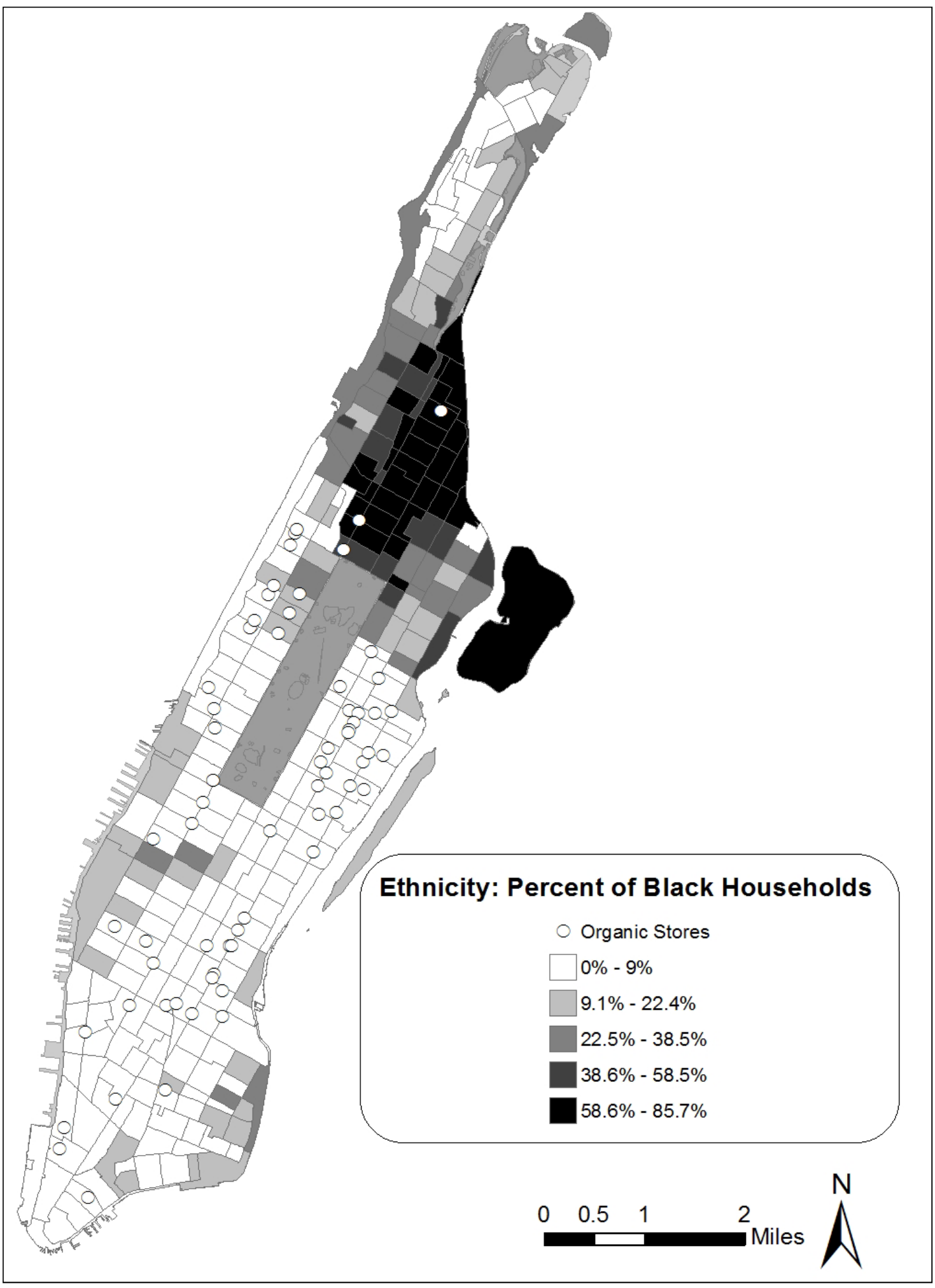

Sources: Data collected by authors; American Community Survey, 2009. 
Recent research relating the likelihood of consuming organic food with income has yielded inconclusive results, with some finding that households with higher income are more likely to buy organic food and others suggesting that income is not statistically related to the likelihood of buying organic food (Durham, 2007;

Govindasamy \& Italia,1990; Loureiro et al., 2001). Because income and education are highly correlated, it is difficult to isolate the effects of education and income on behavior, including food access. Thus, in an effort to gain a full picture of this complex relationship, organic food availability is viewed in the context of the distribution of income, education, and for select income/ education combinations in Manhattan.

Figure 4 presents the findings about the location of organic food stores relative to household income. Using 2009 American Community Survey data, income was grouped into four categories (less than USD30,000, from USD30,000 up to USD75,000, USD75,000 up to USD100,000, and above USD100,000). Each census tract was assigned an income level based on a majority rule; if $40 \%$ of the households in a given tract had income in the USD30,000 to USD75,000 range, and this percentage exceeded that of the other three categories, the census tract was classified as USD30,000 to USD75,000. The most obvious characteristic, in terms of household income, is that the portion of Manhattan that is below the northernmost edge of Central Park is composed of census tracts where a majority of the households have incomes above USD100,000. In contrast, lower-income households populate the area north of this boundary, with the majority having incomes below USD30,000 per year. The stores with more types of organic food, with the exception of four outlets, are located in higher-income census tracts.

Education, in terms of consumer likelihood of purchasing organic food, was the socioeconomic characteristic identified in consumer studies as most closely and universally associated with buying organic food. The map of organic food availability and education levels in Manhattan (figure 5) suggests that retailers are aware of this trend, and nearly all stores with a high level of organic food are located in census tracts with educated consumers. The American Community Survey reports education in 14 categories; these were condensed into the following five categories: less than high school, high school graduate (or GED), some college, college graduate, and postgraduate studies. Again, the level of education assigned to each census tract was based on the level of education attained by the majority of the residents. The bulk of highly educated households live south of the northern edge of Central Park, but there are several census tracts north of Central Park that have highly educated households (this largely, but not completely, coincides with the location of Columbia University and Barnard College).

Figure 6 presents a mapping of select levels of income and education; two categories were included. For comparison, the categories are at the opposite ends of the spectrum. One group consists of highly educated, high-income households, and includes census tracts where at least half of the households have income of USD100,000 or more a year, and $30 \%$ or more of the households have at least an undergraduate college degree. The other group consists of households on the other end of the socioeconomic spectrum, where at least half of the households make less than USD30,000 per year, and at least $30 \%$ of the households did not graduate from high school. The grey census tracts are those that do not fit either of these categories. The patterns between income and education suggest much about the availability of organic food: there is no access to organic food in the lowincome, less educated census tracts. Stores are located either in tracts with high levels of income and education (which are likely to have high rents) or bordering on these tracts, where rents are likely to be lower or zoning regulations more accommodating to food stores.

\section{Statistical Assessment of Organic Food Availability and Socioeconomic Characteristics}

Mapping is a wonderful way to present spatial data visually, but on their own maps reveal no information about the statistical significance of the relationships. One method for assessing the statistical relationship between two variables is a 
Figure 4. Organic Food Availability and Income, Manhattan, New York, January 2011

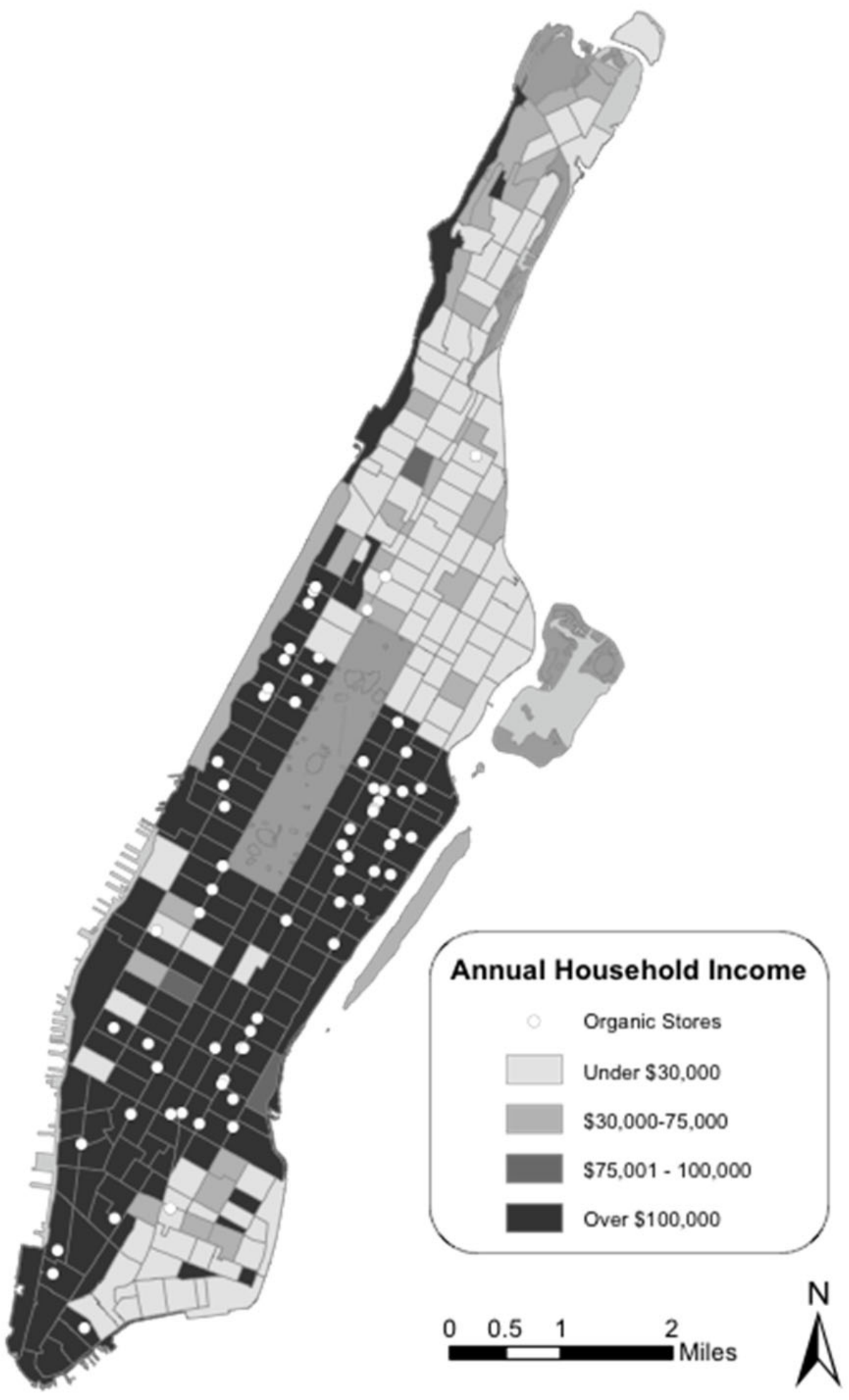

Sources: Data collected by authors; American Community Survey, 2009. 
Figure 5. Organic Food Availability and Educational Attainment, Manhattan, New York, January 2011

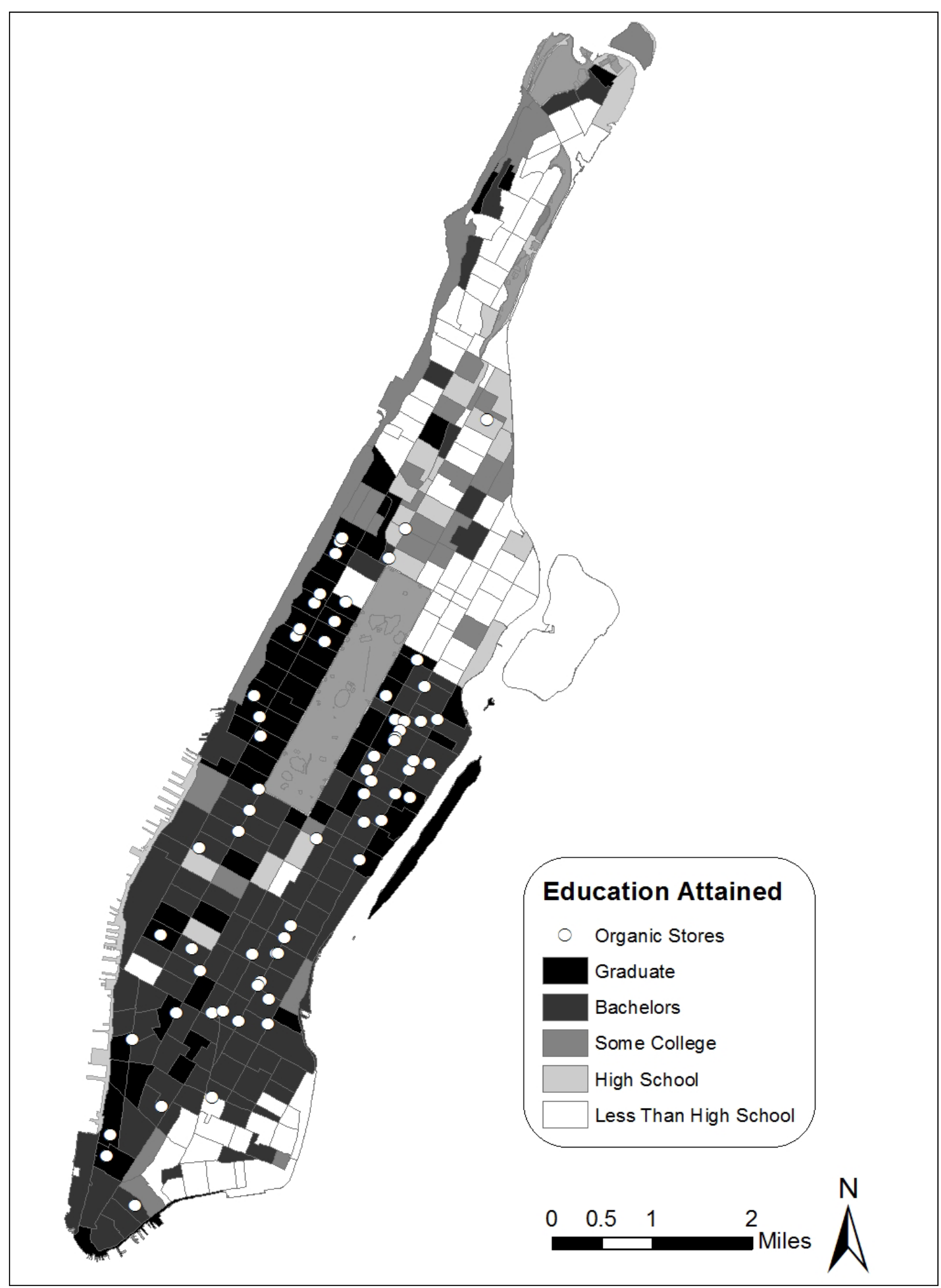

Sources: Data collected by authors; American Community Survey, 2009. 
Figure 6. Organic Food Availability by Income and Educational Attainment, Manhattan, New York, January 2011

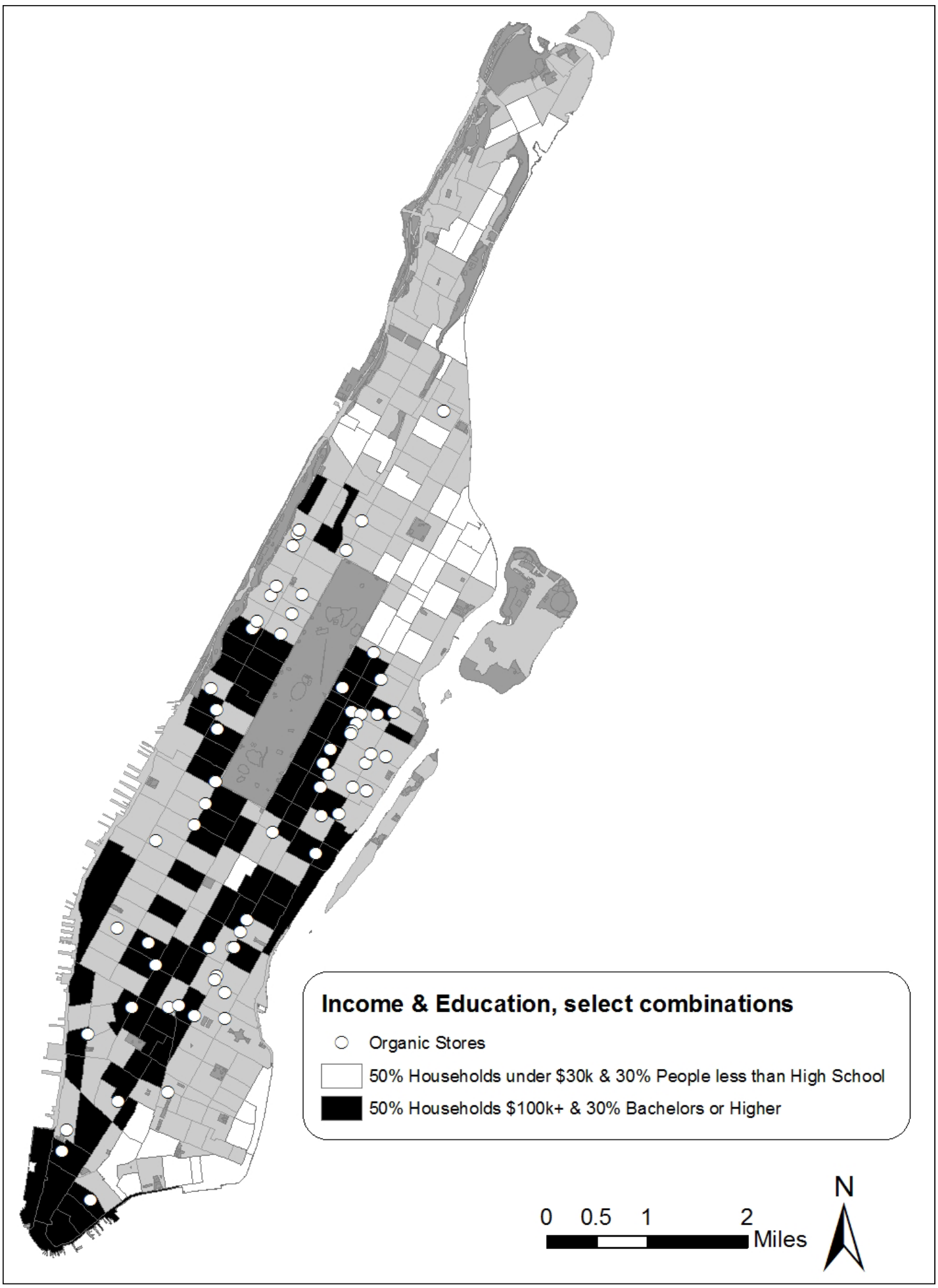

Sources: Data collected by authors; American Community Survey, 2009. 
bivariate correlation coefficient. Bounded between -1 and 1 , this statistic assesses whether there exists a linear relationship between two variables, the direction of the relationship, and the strength of the relationship. The sign indicates whether there is an inverse or positive relationship, and the value indicates the strength of the relationship. Table 2 presents the estimated correlation coefficients between the organic index (the measure of availability) and demographic characteristics. The statistical findings lend support to the findings suggested by the maps, and further are supportive of the research into consumers of organic food.

The education variables reflect a spectrum of educational levels, and range from percentage of households in a census tract that have less than a high school education to the percentage of households in a census tract who hold a post graduate degree. The sign of the correlation coefficient is both negative and statistically significant for the lower levels of education, suggesting that fewer organic products are available in tracts with less educated households. As the level of education increases, the correlation coefficient increases. A statistically significant relationship was not found between the percentage of households with some

\section{Table 2. Bivariate Correlation Coefficients Between Organic Food Index and Demographic Characteristics, Manhattan, New York, 2011} $(\mathrm{N}=1,256)$

\begin{tabular}{lcc}
\hline $\begin{array}{l}\text { Demographic } \\
\text { characteristic }\end{array}$ & $\begin{array}{l}\text { Estimated } \\
\text { correlation } \\
\text { coefficient }\end{array}$ & p-value \\
\hline Education & & \\
\hline Less than high school & -0.27 & 0.0001 \\
\hline Graduated high school & -0.24 & 0.0001 \\
\hline Some college & 0.02 & 0.4785 \\
\hline College graduate & 0.26 & 0.0001 \\
\hline Postgraduate degree & 0.26 & 0.0001 \\
\hline Black as sole race & -0.15 & 0.0001 \\
\hline Median income & 0.32 & 0.0001 \\
\hline
\end{tabular}

Notes: The analysis was conducted at the census-tract level. Reported $p$ value is for a two-tailed test.

Sources: American Community Survey, 2009; data collected by the authors. college and organic food availability. The relationship between percentage of households with college baccalaureate degrees and availability of organic food was positive and significant. Median income of the households in a census tract was also positively correlated with availability of organic food, while the percentage of black households was negatively correlated. However, the relationship between the percentage of black households and organic food availability, while negative, is not very strong.

Overall, the findings indicate that as the percentage of educated households in a census tract increases, so does the availability of organic food (although causality was not directly estimated). The value of estimated correlation coefficients increases along with the level of education. That said, the values of the correlation coefficients for the variables are in the range of weak to medium, suggesting that while these demographic characteristics are correlated with organic food availability, other factors must matter as well.

\section{Conclusions}

This research is an important first step toward understanding several important unresolved issues in the literature regarding access to sustainably produced food. First, the work is an on-the-ground examination of how the tension between food access and sustainably produced food plays out in the marketplace. Not surprisingly, areas with few food stores and with a narrow range of food available for sale also have very little organic food available. Second, the research also is an initial effort to integrate the notion of availability into the organic food literature. Consumers are clearly not able to buy organic food if it is not easily accessible, and studies of demand for organic food would be both refined and enhanced if measures of availability were incorporated.

It is important to keep in mind that retailer decisions about store location, shelf-space allocation, and optimal product mix are complex, and clearly play a crucial role in the availability of organic food. The outcome of store decisions thus forms the underpinnings of the geographic clustering of organic food availability. The spatial patterns 
of indices of organic food availability, created from data collected in store, are strongly suggestive that the availability of organic food varies with both income and education. The mappings indicate that stores located in neighborhoods that have a population that is both high-income and highly educated carry more organic food than those located in census tracts with less affluent and relatively less educated households. Further, the mappings reveal that black households have low access to organic food. The maps' suggested findings are confirmed by bivariate correlation coefficients. Some of the findings confirm previous research: areas with mainly black residents and low-income households generally do not have healthy food available for sale, and this was true for the healthy, organic food products studied. This finding might contribute further to an explanation of why studies find that black households are not likely to buy organic food.

Our results raise multiple questions while indicating that integrating availability into the literature promises to be fruitful. Several possible future directions are evident. The first avenue is to conduct an analysis that permits an examination of multiple factors simultaneously, as well as factors in the spatial implications of zoning regulations, land prices, and other neighborhood characteristics. This approach would develop a more spatially explicit model to explain patterns of organic food availability. A second direction would model consumer demand for organic food, incorporating techniques of spatial analysis to capture both traditional demand factors (such as food prices and household income) and spatial factors (such as land values, zoning, and neighborhood characteristics); this line of research is similar in spirit to the economic geography research conducted in land use and farmland preservation models.

Broadening the types of products studied to include local food, fair-trade products, or food with other labels would provide a spatial exploration of food with a wider range of desirable attributes. This line of research would expand the discussion from access to organic food to access to sustainable food, which would be a complex task. Venturing into the availability of sustainable food requires significant up-front work in defining sustainably produced and marketed food, as well a mechanism for sorting out foods that fail to meet their promise of being sustainable.

The future research proposed, which is both exciting and promising, requires extensive additional primary data collection; if successful, our understanding will expand tremendously. Our hope is that this paper will not only spur a new line of research into this area, but perhaps more importantly will open a discussion between those working on food access and those interested in food system sustainability.

\section{Acknowledgements}

The authors are grateful for the data collection support for the census of food stores in Manhattan provided by the students in the Food Studies program at New York University, in particular the students in Professor Dimitri's Food Systems I, Fall 2010, class. The data on organic food availability in Manhattan was collected by Erik Bielsky, Julia Ficht, Krystal Ford, Laura Mirsch, and Stephanie Rogus. They bravely faced single-digit temperatures as they collected the data in Manhattan during January 2011, and I thank them for their efforts. The project design benefited from numerous discussions with my colleagues Lydia Oberholtzer (Penn State) and Jacqueline Geoghegan (Clark University), who are working on similar efforts in their jurisdictions. We thank four anonymous reviewers for insightful feedback; responsibility for any remaining errors remains with the authors.

\section{References}

Agricultural Marketing Service, U.S. Department of Agriculture. (2011). Farmers market search. Retrieved from http://search.ams.usda.gov/farmersmarkets/

Besharov, D. J., Bitler, M., \& Haider, S. J. (2011). An economic view of food deserts in the United States. Journal of Policy Analysis and Management, 30(1), 153176.

Dettmann, R. L., \& Dimitri, C. (2010). Who's buying organic vegetables? Demographic characteristics of U.S. consumers. Journal of Food Products Marketing, 16(1), 79-81. http://dx.doi.org/10.1080/10454440903415709 
Dimitri, C., \& Dettmann, R. L. (In press). Organic food consumers: What do we know? British Food Journal.

Drewnowski, A., \& Eichelsdoefer, P. (2009). Can lowincome Americans afford a healthy diet? (Center for Public Health Nutrition Public Health Research Brief). Retrieved from http://depts.washington. edu/uwcphn/reports/brief1.pdf

Durham, C. (2007). The impact of environmental and health motivations on the organic share of purchases. Agricultural and Resource Economics Review, 36(2), 304-320.

Economic Research Service, USDA. (2011). Food environment atlas. Retrieved from http://www.ers.usda.gov/foodatlas/

Fotopolous, C., \& Krystallis, A. (2002). Purchasing motives and profile of the Greek organic consumer: A countrywide survey. British Food Journal, 104(9), $730-765$. http://dx.doi.org/10.1108/00070700210443110

Fromartz, S. (2006). Organic Inc.: Natural foods and how they grew. Florida: Houghton Mifflin Harcourt.

Ghirardelli, A., Quinn, V., \& Foerster, S. B. (2010). Using geographic information systems and local food store data in California's low-income neighborhoods to inform community initiatives and resources. American Journal of Public Health, 100(11), 2156-2162. http://dx.doi.org/10.2105/AJPH.2010.192757

Govindasamy, R., \& Italia, J. (1990). Predicting willingness to pay a premium for organically grown fresh produce. Journal of Food Distribution Research, 30(2), 44-53.

Greene, C., Dimitri, C., Lin, B-H., McBride, W., Oberholtzer, L., \& Smith, T. (2009). Emerging issues in the U.S. organic industry (Economic Information Bulletin No. 55). Washington, D.C.: Economic Research Service, U.S. Department of Agriculture.

The Hartman Group. (2008, July 23). Organics today: Who's buying and what's next. Retrieved from http://www.hartman-group.com/hartbeat/2008$\underline{07-23}$

Howard, P. H. (2009). Consolidation in the North American organic food processing sector, 1997 to 2007. International Journal of Sociology of Agriculture and Food, 16(1), 13-30.

Kirkpatrick, S. I., \& Tarasek, V. (2010). Assessing the relevance of neighbourhood characteristics to the household food security of low-income Toronto families. Public Health Nutrition, 13, 1139-1148. http://dx.doi.org/10.1017/S1368980010000339

Kirschenmann, F., Stevenson, G. W., Buttel, F., Lyson, T. A., \& Duffy, M. (2008). Why worry about agriculture in the middle? In T. A. Lyson, G. W. Stevenson, \& R. Welsh (Eds.), Food and the mid-level farm: Renewing an agriculture of the middle. Cambridge, Massachusetts: Massachusetts Institute of Technology Press.

Krystallis, A., Fotopoulos, C., \& Zotos, Y. (2006). Organic consumers' profile and their willingness to pay (WTP) for selected organic food products in Greece. Journal of International Consumer Marketing, 19(1), 81-106. http://dx.doi.org/10.1300/J046v19n01 05

Loureiro, M., McCluskey, J., \& Mittlehammer, R. (2001). Assessing consumer preferences for organic, ecolabeled, and regular apples. Journal of Agricultural and Resource Economics, 26(2), 404-416.

Magnusson, M. K., Arvola, A., Koivisto Hursti, U. K., \& Åberg, L. (2001). Attitudes towards organic food among Swedish consumers. British Food Journal, 103(3), 209-226. http://dx.doi.org/10.1108/00070700110386755

Nutrition Business Journal. (2010). U.S. Organic Food Sales: 1997-2010, 2011e-2017e-Chart 22.

Boulder: Penton Media.

O’Donovan, P., \& McCarthy, M. (2002). Irish consumer preference for organic meat. British Food Journal, 104(3-5), 353-370. http://dx.doi.org/10.1108/00070700210425778

Pimental, D., \& Pimental, M. (2008). Food, energy and society. Florida: Taylor \& Francis Group.

Pollan, M. (2001, May 13). Beyond the organic industrial complex. New York Times. Retrieved from http://www.nytimes.com/2001/05/13/magazine/ 13ORGANIC.html?pagewanted $=$ all

Powell, L. M., Slater, S., Mirtcheva, D., Bao, Y., \& Chaloupka, F. J. (2007). Food store availability and neighborhood characteristics in the United States. Preventive Medicine, 44(3), 189-195. http://dx.doi.org/10.1016/j.ypmed.2006.08.008

Rose, D., Bodor, J. N., \& Rice, J. C. (2011). The effects of Hurricane Katrina on food access disparities in New Orleans. American Journal of Public Health, 101(3), 482-484. http://dx.doi.org/10.2105/AJPH.2010.196659 
Tilman, D., Cassman, K. G., Matson, P. A., Naylor, R., \& Polasky, S. (2002). Agricultural sustainability and intensive production practices. Nature, 418(8), 671677. http://dx.doi.org/10.1038/nature01014

U.S. Bureau of the Census. (2009). Educational attainment (S1501); Housebold income in the past 12 months (B19001); Race (B02001). American Community Survey. Available online at http://www.census.gov/acs/www/

U.S. Census Bureau. (2011). Tenure by vehicles available. Manhattan, NYC. B25044. American Fact Finder. American Community Survey.
U.S. Census Bureau. (2011). State and County QuickFacts: New York County, NY. Retrieved from http://quickfacts.census.gov/qfd/states/36/ 36061.html

U.S. Census Bureau. (2004). People: Race and ethnicity: The face of our population. Retrieved from http://factfinder.census.gov/isp/saff/SAFFInfo. jsp? pageId $=$ tp 9 race ethnicity

Zepeda, L., \& Li, J. (2007). Characteristics of organic food shoppers. Journal of Agricultural and Applied Economics, 39(1), 17-28. 